\title{
Território, certificação de procedência e a busca da singularidade: o caso do Café do Cerrado
}

\author{
Antonio César Ortega* \\ Clésio Marcelino Jesus**
}

\section{Resumo}

Este artigo analisa a experiência do arranjo produtivo territorial organizado pelos cafeicultores do oeste do estado de Minas Gerais (Brasil), que, por meio de suas associações de produtores municipais, constituíram o Conselho das Associações dos Cafeicultores do Cerrado Mineiro (Caccer), que obteve, em 2005, o reconhecimento da Indicação Geográfica de seu café, e pôde passar a emitir a Certificação de Procedência Café do Cerrado. Desde então, cabe ao Caccer atestar a qualidade da produção de seus filiados que atendam às especificações exigidas por aquela certificação. O Café do Cerrado constituiu-se, assim, na primeira região de origem produtora de café demarcada do país. O sucesso daquela cafeicultura está ligado à constituição de um arranjo produtivo territorial rural, bastante institucionalizado, cuja inserção nos mercados nacional e global é cada vez mais expressiva. Porém, há que se reconhecer que esse processo tem causado diferenciação entre os produtores, entre os que têm e os que não têm conseguido acompanhar as exigências estabelecidas pela certificação de origem.

Palavras-chave: cafeicultura, Café do Cerrado, certificação de origem, nova sociologia econômica, desenvolvimento territorial.

Professor Associado III do Instituto de Economia da Universidade Federal de Uberlândia. Agradeço ao CNPq e Fapemig que financiaram de diferentes maneiras a pesquisa que viabilizou esse artigo. Endereço eletrônico: acortega@ufu.br.

*** Doutorando em Economia na Universidade Federal de Uberlândia, pesquisador do Núcleo de Estudos Rurais do Instituto de Economia da Universidade Federal de Uberlândia. Endereço eletrônico: clesiomj@yahoo.com.br. 
Território, certificação de procedência e a busca da singularidade:

\section{Introdução}

$\mathrm{N}$

o Cerrado Mineiro ${ }^{1}$, oeste do estado de Minas Gerais, encontra-se uma das experiências mais bem sucedidas de arranjo produtivo territorial rural do Brasil. Organizado pelos cafeicultores, por meio de suas associações de produtores municipais, o Conselho das Associações dos Cafeicultores do Cerrado Mineiro (Caccer) obteve, em 2005, o reconhecimento da Indicação Geográfica do produto e emite a Certificação de Procedência Café do Cerrado. Desde então, cabe ao Caccer atestar a qualidade da produção de seus filiados que atendam às especificações exigidas por algumas empresas certificadoras, constituído, na primeira região de origem produtora de café demarcada no país.

Desde o início da década dos noventa do século passado, a cafeicultura nacional passou a conviver com o processo de desregulamentação do setor. Naquele momento, ocorreu a extinção do Instituto Brasileiro do Café (IBC) e a retirada do Brasil dos acordos internacionais, o que levaria o setor a uma profunda crise. Como consequência do fim dos acordos internacionais, observou-se a entrada de novos concorrentes no mercado mundial e a redução dos preços do produto.

Para enfrentar essa nova realidade, emergiram importantes experiências autônomas de concertação social com vistas a reocupar os espaços de intervenção que, antes, eram ocupados pelo Estado. Exemplo disso é o caso do Caccer. Uma experiência resultante de uma nova etapa do associativismo rural no Brasil, em que os agricultores se organizam em função do produto na qual se especializaram e da região em que atuam. Essas organizações representativas, de caráter especializado, retiram boa parte do protagonismo da representação de interesses rural, antes exercido por organizações sindicais de caráter unitário (ORTEGA, 2005).

1 Estamos associando o Cerrado Mineiro às microrregiões do Noroeste de Minas, Paracatu, Pirapora, Uberlândia, Patrocínio, Patos de Minas, Uberaba, Araxá e Piauí, envolvendo 55 municípios. Evidentemente que a abrangência das terras de cerrado no estado de Minas Gerais é maior do que as que se concentram nessas microrregiões. O uso daquela expressão, portanto, está ligado ao fato de que nessas microrregiões é que se concentra a produção de café em terras de cerrado em Minas Gerais. 
Assim, ao analisar o caso do Café do Cerrado em Minas Gerais, tomamos como hipótese que o sucesso daquela atividade está ligado à constituição de um arranjo produtivo territorial rural, bastante institucionalizado, cuja inserção nos mercados nacional e global é cada vez mais expressiva, e foi favorecida pela maior competitividade conferida pela Indicação Geográfica do café.

Neste artigo, portanto, apresentamos resultados de um estudo sobre o surgimento de um arranjo produtivo de base territorial, constituída de maneira autônoma e privada, com vistas a uma melhor inserção nos mercados nacional e internacional de café. Este é o caso do Conselho das Associações dos Cafeicultores do Cerrado (Caccer) no oeste do estado de Minas Gerais, que conquistou o reconhecimento de sua delimitação geográfica e a denominação de origem Café do Cerrado.

\section{Metodologia}

Esse artigo é resultado de pesquisa realizada com apoio da Fapemig, por meio do Programa Pesquisador Mineiro. A metodologia utilizada privilegiou, em suas investigações, as abordagens qualitativas de pesquisa, apesar de evitar a dicotomia qualitativo-quantitativa nos delineamentos e tratamentos das diferentes temáticas. Seguindo essa perspectiva, utilizamos amplo acervo de fontes bibliográficas, documentos oficiais das instituições representativas da cafeicultura do Cerrado Mineiro (organizações intermunicipais e o Caccer), dados estatísticos primários, obtidos por meio de aplicação de questionário em universo representativo, principalmente, durante os encontros promovidos pelas associações de produtores, e secundários (Censos Agropecuários e Rais-Caged).

Por meio de entrevistas orais temáticas foram registrados depoimentos de empresários de diferentes segmentos da cadeia produtiva (empresários rurais, industriais e do setor de serviços, particularmente junto às empresas terceirizadoras das atividades de mecanização). Além desses, entrevistamos seus representantes, membros de associações de produtores, cooperativas, sindicatos e 
Território, certificação de procedência e a busca da singularidade:

o caso do Café do Cerrado

Conselho das Associações. Por último, ainda entrevistamos técnicos e pesquisadores.

Para realização dessas entrevistas utilizamos diferentes modelos de questionários previamente estruturados, que serviram de roteiro das entrevistas gravadas. As fontes orais representam uma possibilidade real de troca de experiências, de diálogo, de registro, preservação e crítica das diferentes experiências dos atores sociais territoriais. Constitui assim, mais que um procedimento técnico de pesquisa.

O critério de seleção dos entrevistados, líderes e produtores típicos ${ }^{2}$ privilegiou a heterogeneidade. Os dados foram sistematizados, analisados em diálogo com a teoria, de acordo com os objetivos delineados.

\section{O enfoque territorial e estruturas de governança}

A última década do século XX esteve marcada pelo entusiasmo com que os defensores do mainstream econômico anunciavam o "fim da história" e das fronteiras. Entretanto, neste início de milênio, o que se observa, na verdade, contrariando aqueles prognósticos, é a emergência de novos espaços de construção de projetos de desenvolvimento de base territorial.

Dessa maneira, vimos constituir, nos últimos anos, no Brasil, tanto arranjos sócio-produtivos territoriais, induzidos por políticas públicas, como a consolidação de estruturas de governança privadas, também de base territorial, e que vêm coordenando cadeias produtivas para ampliação da escala, com vista a uma maior capacidade de competitividade nos mais dinâmicos mercados nacionais e internacionais. Essas estruturas de governança, organizadas privadamente, vêm proliferando-se no Brasil, particularmente,

2 Utilizando a noção de tipos ideais weberianos, selecionamos produtores rurais cuja produção é altamente tecnificada, assim como aqueles que não vêm conseguindo incorporar todas as inovações disponíveis, como é o caso dos agricultores familiares que possuem propriedades de elevada declividade e que não podem introduzir a colheita mecânica. 
em torno de cadeias agroindustriais, como forma de enfrentar as duras realidades de mercados globalizados. Essas experiências, como é o caso do Café do Cerrado no Cerrado Mineiro, buscam consolidar sua atividade, identificando a referência do território em que é produzido para constituir uma denominação de origem.

Portanto, ao contrário do que prognosticavam os arautos do mainstream, temos o fortalecimento dos territórios no mundo globalizado, e não o fim das fronteiras e dos territórios. De acordo com Haesbaert (2006), o fenômeno da desterritorialização, como consequência do processo de globalização, na verdade, é um mito, e o que assistimos é uma "des(re)territorialização" do mundo ${ }^{3}$. Dessa maneira, em nossas pesquisas, o que temos feito é perscrutar quais são as condições e perspectivas concretas para o desenvolvimento territorial no processo de transformação econômica de globalização. Nesse sentido, as questões a serem respondidas são: como um território pode e deve mover-se dentro de um avassalador processo de mudanças globais em que está inserido? Como as políticas de desenvolvimento territorial podem contribuir com esse desafio?

O uso do enfoque territorial, em tempos de globalização, vem sendo utilizado por cientistas e recomendado por governos e agências multilaterais. $\mathrm{O}$ conceito de território, entretanto, é um desses conceitos que adquiriu um caráter polissêmico e, portanto, precisa ser claramente definido para seu uso.

As recentes políticas públicas de desenvolvimento rural, que usam o critério territorial em sua implementação, fazem-no a partir do incentivo à constituição de territórios zonas, ou seja, sua adoção em espaços geográficos contínuos. Apreendemos, portanto, por territórios os espaços delimitados, onde se praticam dife-

3 "O mito da desterritorialização é o mito dos que imaginam que o homem pode viver sem território, que a sociedade pode existir sem territorialidade, como se o movimento de destruição de territórios não fosse sempre, de algum modo, sua reconstrução em novas bases... [Desse modo], o grande dilema desse início de milênio, [...], não é o fenômeno da desterritorialização, [...], mas o da multiterritorialização, [...], de experimentar diferentes territórios ao mesmo tempo, reconstruindo constantemente o nosso" (HAESBAERT, 2006). 
Território, certificação de procedência e a busca da singularidade:

o caso do Café do Cerrado

Clésio Marcelino Jesus

rentes tipos de intercâmbio em seu interior (inclusive de poder) e com o exterior (outros territórios, localidades, espaços regionais ou nacionais e a economia internacional), numa perspectiva de competitividade territorial, que combina dimensões econômica, social, ambiental e política. (SEPÚLVEDA et al., 2003). Como consequência, utiliza-se a noção de território como uma "construção territorial, e pressupõe um projeto (de escala regional/territorial) concertado socialmente e detonador do desenvolvimento" (MOHAR, 2008:25).

Apesar de o modismo levar à banalização do conceito, nossa intenção é verificar a pertinência do uso do enfoque territorial em processo de des (re)territorialização em virtude do avanço da globalização. A desterritorialização é uma das características apontadas como consequência do processo de globalização, na medida em que se alcançaria uma "cidadania universal", e as fronteiras perderiam sentido. Nessa perspectiva, toma-se como pressuposto a deslocalização econômica, a fragilização das fronteiras políticas (inclusive, as nacionais) e o hibridismo cultural para caracterizá-lo. Seria, neste caso, o próprio "fim dos territórios" ${ }^{4}$

Ao contrário, e concordando com Haesbaert (2006:32):

defendemos a ideia de que muito do que os autores denominam desterritorialização é, na verdade, a intensificação da territorialização no sentido de uma 'multiterritorialidade', um processo concomitante de destruição e construção de territórios mesclando diferentes modalidades territoriais (como os 'territórios-zona' e os 'territórios-rede'), em múltiplas escalas e novas formas de articulação territorial.

Nessa perspectiva, questionamos a homogeneização esperada por muitos em decorrência do processo de globalização, ressaltando, portanto, sua não linearidade e seu não monolitismo. Pois, como enfatiza Reis (2002), ainda que aceitemos a tese da convergência provocada pela globalização, precisamos reconhecer, entretanto, a capacidade de iniciativas territoriais em se tornarem globais. Ou seja, para o pesquisador português, "a noção de globa-

4 Sobre o tema, pode-se consultar Haesbaert (2006), particularmente, capítulos 2 e 3. 
lização só pode ser útil se estiver dotada de qualidades que lhe permitam apreender as dinâmicas do mundo", e que não é única. Portanto, é preciso reconhecer que o processo de globalização impacta os diferentes territórios, que reagem de distintas maneiras.

Evidentemente que, assim como fazem os autores citados, não negamos a amplitude das relações hierárquicas que estruturam a economia mundial, mas o que questionamos são as potencialidades dos territórios, por meio de ações coletivas, para promoverem o desenvolvimento (locais/territoriais). Em outras palavras, o que estamos buscando compreender são as possibilidades para o desenvolvimento endógeno de economias de dinâmicas territorializadas, assentadas na cooperação, em aprendizagem, conhecimentos tácitos e culturas técnicas específicas e em inter-relações sinérgicas (REIS, 2002:116).

\section{A cafeicultura no Cerrado Mineiro}

A região do Cerrado Mineiro possui uma temperatura média de $18^{\circ} \mathrm{C}$ a $23^{\circ} \mathrm{C}$, uma altitude de produção cafeeira de 800 a 1.300 metros acima do nível do mar e um índice pluviométrico médio de 1600 milímetros anuais, com baixa umidade relativa do ar no período da colheita. Somadas às características do relevo, essas são condições bastante favoráveis ao cultivo do café. Não é à toa que os 158.954 hectares de café plantados naquela área (EMATER, 2008), e distribuídos por 55 municípios do Cerrado Mineiro, ofereceram uma produção de 4.004 .700 sacas de $60 \mathrm{Kg}$ no ano de 2008. Concentrando $14,94 \%$ da área plantada e $18,47 \%$ da produção do estado, com uma produtividade média de 27,44 sacas por hectares, enquanto a média estadual foi de 22,20 sacas em 2008. Demonstra-se, assim, essa cafeicultura, elevada produtividade em relação ao estado.

O café foi introduzido de maneira intensa na região com a política de modernização da cafeicultura brasileira, iniciada em 1969, depois de forte geada no norte do Paraná e oeste de São Paulo. Com o objetivo de erradicar os cafeeiros com baixa produtividade e cultivados em regiões sujeitas a geadas, foi implementa- 
Território, certificação de procedência e a busca da singularidade:

do o Plano de Renovação e Revigoramento dos Cafezais (PRRC), conhecido pelo lema "Renovar para Salvar". Com o PRRC, o Cerrado Mineiro tornou-se a região prioritária de incentivo à cafeicultura nacional.

Até os anos 1970, a produção de café no Cerrado Mineiro destinava-se, basicamente, ao consumo próprio. Mas, com os resultados obtidos (ampliação da área plantada, uso de tecnologias modernas, elevada produção, produtividade e melhoria da qualidade), o café passou a ser dirigido essencialmente para a exportação. Dessa maneira, ocorrem, desde 1970, transformações na cafeicultura do Cerrado Mineiro que contribuíram imensamente para o desenvolvimento dessa atividade, concorrendo positivamente para a balança comercial, com base em:

a. Planos de incentivo à ocupação de novas fronteiras agrícolas, ocasionando a migração de produtores do Sul e Sudeste do país para o Triângulo Mineiro, Alto Paranaíba e Noroeste de Minas;

b. Financiamento da compra de terras para novos colonos;

c. Políticas de crédito agrícolas do Sistema Nacional de Crédito Rural.

d. Pesquisas científicas, principalmente públicas, mas também privadas, que resultaram em inovações biológicas, agronômicas, mecânicas e físico-químicas.

Com relação à estruturação produtiva, para sua introdução, foi preciso que as terras de cerrado fossem "adaptadas". Seus solos ácidos e pobres em nutrientes foram transformados para se adequarem ao cultivo do café. Assim, é preciso reconhecer que as inovações físico-químicas foram fundamentais para o desenvolvimento da cafeicultura no Cerrado Mineiro. Por meio delas, foram realizadas correções no solo, com aração e gradagem da terra, aplicação de calcário, adubação orgânica, com nutrientes (fosfato, nitrogênio e potássio) e micronutrientes (sulfato de zinco e ácido bórico) necessários ao desenvolvimento da planta.

Além disso, merece destaque, também, as inovações biológicas, particularmente novas variedades de plantas que possam 
ser bem exploradas pelas máquinas. Por exemplo, são introduzidas plantas com facilidade de desprendimento dos grãos da rama, com porte baixo, galhos distribuídos de forma mais uniforme e presença de maturação precoce, semiprecoce e tardia. Logo, estas características facilitam o deslocamento da máquina na lavoura, fruto de importantes inovações mecânicas.

A introdução dessas inovações foi possível, ainda, em função da adoção de determinadas inovações agronômicas, que permitiram grandes modificações no método de plantio, no manejo e nos tratos culturais, possibilitando o aumento de produção e produtividade, bem como da ampliação do uso de máquinas e equipamentos agrícolas. Aliado a tais inovações, o clima e as características do relevo do Cerrado Mineiro propiciam condições bastante favoráveis ao cultivo do café.

O Cerrado Mineiro é uma das poucas regiões do mundo a produzir cafés naturais, ou seja, aqueles que são secos com casca. Isso se deve, em grande parte, ao inverno extremamente seco, com temperaturas amenas, coincidindo com o período de colheita do café. As características básicas da bebida do Café do Cerrado são: aroma intenso, com notas variando entre caramelo e nozes, acidez delicada, predominantemente cítrica, corpo variando de mediano a encorpado, sabor adocicado e achocolatado intenso e finalização de longa duração (www.cafedocerrado.org).

Desde o início da década dos noventa do século passado, a cafeicultura nacional passou a conviver com o processo de desregulamentação do setor. Naquele momento, ocorreu a extinção do Instituto Brasileiro do Café (IBC) e a retirada do Brasil dos acordos internacionais, o que levaria o setor a uma profunda crise, ao contrário do que esperavam o governo, os empresários e os representantes do setor, houve uma forte articulação em torno da cadeia no Cerrado Mineiro (ORTEGA, 2000 e 2005).

O fim dos acordos internacionais possibilitou a entrada de novos concorrentes e a redução dos preços do produto. O enfrentamento dessa nova situação, por parte dos produtores e exportadores nacionais, viu-se dificultado em face da inexistência da ação 


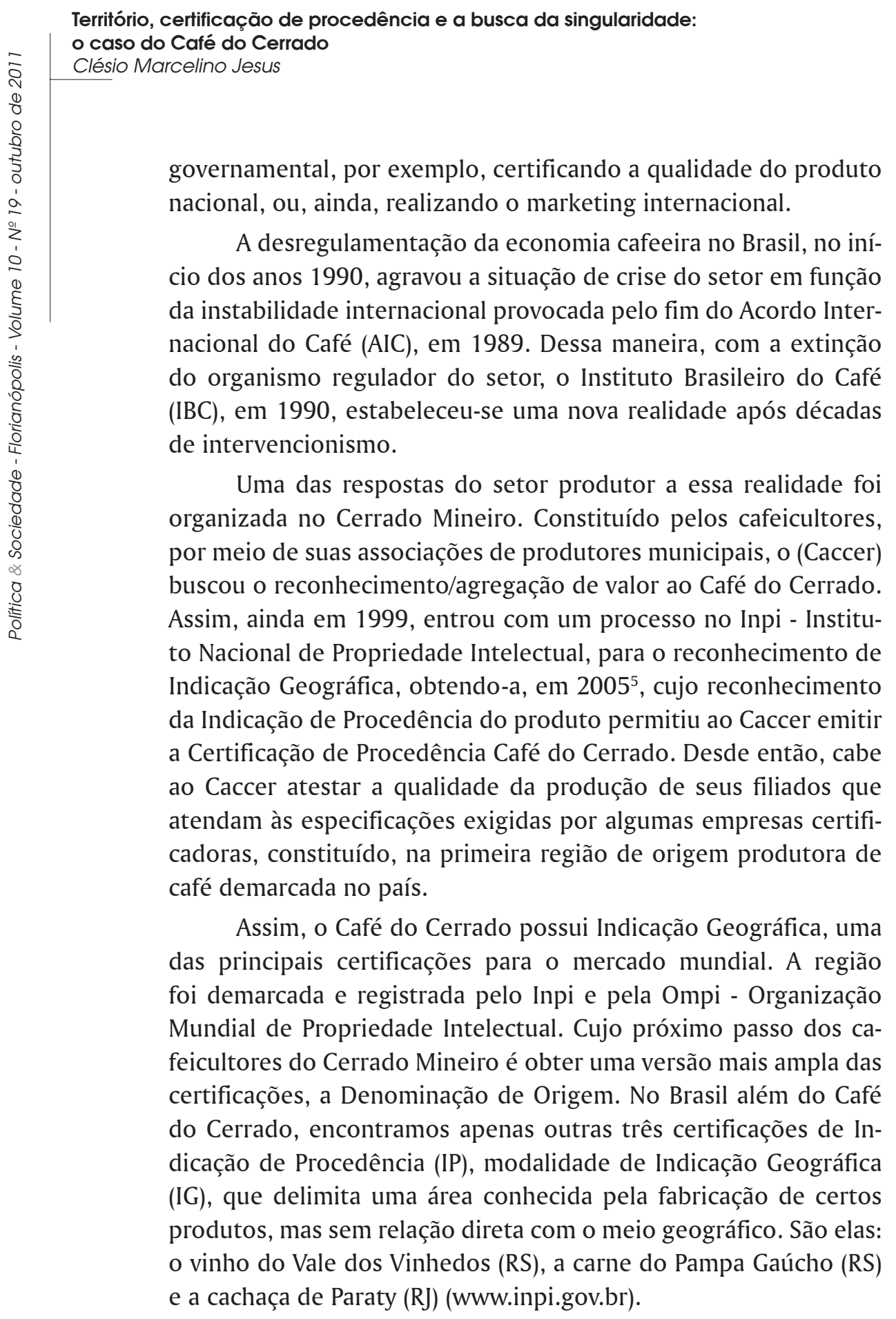

5 Publicação da Concessão: RPI n ${ }^{\circ}$ 1797, 14 de maio de 2005. 
A experiência de organização da representação de interesses da cafeicultura do Cerrado Mineiro foi fundamental para viabilizar a constituição de uma estrutura de governança que tem possibilitado estabelecer uma regulação privada de grande êxito para a inserção nos mercados nacionais e internacionais mais exigentes. Essa experiência pode ser interpretada como uma nova etapa do associativismo rural no Brasil, em que os agricultores se organizam em função do produto em que se especializaram, dando às entidades representativas, de caráter especializado, o protagonismo da representação de interesses rurais (ORTEGA, 2005:157-182).

Assim, ao analisar o caso do Café do Cerrado em Minas Gerais, reconhecemos que o sucesso daquela atividade está ligado à constituição de um arranjo produtivo territorial rural, bastante institucionalizado ${ }^{6}$, cuja inserção nos mercados nacional e global é cada vez mais expressiva, o que justifica a investigação e a produção de novos conhecimentos sobre o tema.

É certo que a certificação de origem favoreceu a maior competitividade da cafeicultura do Cerrado Mineiro nos mercados globais mais exigentes, por outro lado, também há que se reconhecer que esse processo tem causado diferenciação entre os produtores e desemprego rural em virtude da intensificação da mecanização, principalmente da colheita (ORTEGA e MOURO, 2007).

\section{Território do Café do Cerrado}

A experiência de organização representativa, por meio das associações dos cafeicultores do Cerrado Mineiro, pode ser interpretada como uma nova etapa do associativismo, em que os agricultores se organizam segundo a Certificação de Procedência. Suas entidades representativas, além de defenderem os interes-

6 "Por 'instituição' designamos as regras partilhadas, sob a forma de leis ou de entendimentos coletivos, mantidos por hábito, acordo explícito ou acordo tácito. Estas instituições - que assumem a forma de direitos de propriedade, estruturas de governação, concepções de controlo ou normas de transação - permitem que os actores envolvidos nos mercados se organizem e desenvolvam entre si relações de competição, cooperação e transação." (FLIGSTEIN, 2003:198) 
Território, certificação de procedência e a busca da singularidade:

ses dos associados, proporcionam assistência técnica, política de marketing, comercialização e uma ação que podemos chamar de auto-fiscalização, a fim de melhorar a qualidade do produto - um claro exemplo de regulação privada.

Fazem parte da região demarcada nos 55 municípios, 3.516 cafeicultores e 4.546 propriedades, que ocupam 155.000 hectares de café, de acordo com informações do Caccer (CACCER, 2006).

A origem da experiência inovadora promovida pelos cafeicultores do Cerrado Mineiro, que levou à criação do Caccer, deve ser buscada em 1986, quando foi fundada a primeira associação de cafeicultores do Cerrado, no município de Araguari: a Associação dos Cafeicultores de Araguari (ACA). Antes que terminasse a década de 80, mais uma associação foi criada na região: a Associação de Apoio aos Produtores Rurais da Região de São Gotardo (Assogotardo), cuja atenção se voltava, em especial, à cafeicultura, já que o Plano de Apoio ao Desenvolvimento Agropecuário - o Padap, implementado pelo governo mineiro, nos anos 70 - atraíra agricultores com experiência na cafeicultura que fugia das tradicionais zonas produtoras - São Paulo e Paraná, submetidas constantemente a geadas -, para promover uma nova ocupação do cerrado ${ }^{7}$.

No início da década de 90, proliferaram as associações por toda a região. Em 1990, foi criada, no município de Patrocínio, a Associação dos Cafeicultores da Região de Patrocínio (Acarpa); em 1991, foram instituídas a Associação dos Cafeicultores de Carmo do Paranaíba (Assocafé), a Associação dos Cafeicultores de Monte Carmelo (Amoca), a Associação dos Cafeicultores de Coromandel (Assocoró). As últimas associações criadas na região foram a Associação dos Cafeicultores de Campos Altos e Região (Accar), em 1993; a Associação dos Cafeicultores do Nordeste Mineiro (Acanor), em 1997; e a Associação dos Cafeicultores de Sacramento (Acasa), em 1998.

Fosse pelas questões de conquista de espaço político, fosse pelas demandas específicas que tinham em virtude de sua ativida-

7 Para o tema, pode-se consultar Salim (1986), Ribeiro (1985) e Pessoa (1996). 
de agrícola, o certo é que os cafeicultores da região do Cerrado Mineiro buscaram novas formas de associativismo e criaram o Caccer, cujos objetivos incluem representar os interesses dos cafeicultores da região nos níveis políticos, comercial, social, de marketing e pesquisa.

A exemplo de vários segmentos da agricultura, como ressaltamos anteriormente, a representação setorial na cafeicultura torna-se hegemônica e paralela à representação sindical formal, de caráter unitário. Mas daí surge um problema: obter financiamento para manter essas entidades de maneira independente dos recursos da contribuição obrigatória - direcionados integralmente à representação formal. $\mathrm{O}$ financiamento para a manutenção das entidades representativas da cafeicultura do Cerrado Mineiro viria por meio de contribuições mensais dos cafeicultores, diferenciadas segundo o tamanho da propriedade, e de outras fontes de receitas, que determinariam o valor da contribuição. Assim, eles são enquadrados como minifundistas - até 10 hectares; pequenos cafeicultores - de 10 a 20 hectares; médios cafeicultores — de 20 a 50 hectares; e grandes cafeicultores - acima de 50 hectares.

0 grau de representatividade para as associações que compõem o Caccer está na casa dos $60 \%$, considerado pelos seus dirigentes e por nós com sendo um bom índice, principalmente se considerarmos que o pagamento da contribuição sindical obrigatória atua como desestimulador da dupla afiliação. O financiamento por meio de filiação voluntária, entretanto, tem restringido algumas associações. Exatamente por isso, uma ação mais incisiva na defesa dos interesses dos filiados prepondera na garantia de elevado nível de filiação, somada às ofertas de serviços; com isso, tenta-se garantir um pequeno índice de free-riders $^{8}$ de sua base social para assegurar financiamento.

8 Nos estudos sociológicos da ação coletiva, a expressão free-rider significa aquele que caminha sozinho, individualmente. Um free-rider é um ator social oportunista, pois procura beneficiar-se dos resultados da ação coletiva quando interessa, mas não colabora com essas ações. 
Território, certificação de procedência e a busca da singularidade:

\section{1. O Caccer e a conquista da Indicação Geográfica}

O Caccer surgiu somente após intensa proliferação de associações de cafeicultores no Cerrado, caracterizadas, como vimos, por uma dificuldade em canalizar os interesses específicos dos cafeicultores. Atividade relativamente recente na região, a cafeicultura incorporou agricultores de outras regiões, com experiências distintas daquelas dos tradicionais produtores do Cerrado, e encontrou dificuldades para uma perfeita integração com a representação de interesses local. Isso os incentivou a constituir as próprias organizações: primeiro, as organizações nos municípios-polo; posteriormente, o conselho das associações (Caccer). Como filosofia, o Caccer - para não se constituir como cooperativa - buscou preservar a diferenciação de seus associados, à medida que, na comercialização encaminhada pelo conselho, se separa o café de cada produtor para a garantia de preços distintos de acordo com a diferença de cada produto; logo, agricultores que investem na qualidade - fator de diferenciação - lucram mais; tal atitude ajuda a preservar a unidade do conselho, uma base social heterogênea. Essa ação, somada aos serviços oferecidos aos seus afiliados, sempre proporcionou às associações altos índices de afiliação e baixos indicadores quanto ao fenômeno free-rider.

O conselho tem suas origens no $1^{0}$ Seminário Sobre a Cafeicultura na Região dos Cerrados, em julho de 1991, realizado pela Acarpa no município de Patrocínio. Das atividades desenvolvidas atualmente pelo Caccer, merecem destaque: a criação e o registro da marca Café do Cerrado, cuja garantia de qualidade é parte da "Indicação geográfica"; convênios com entidades públicas e privadas para o desenvolvimento de pesquisa, assistência técnica e assessoria para a concessão do certificado de qualidade; criação de uma infraestrutura comercial, com armazéns próprios e a busca de condições especiais para a utilização de armazéns públicos; a promoção do produto mediante campanhas de incentivo ao consumo de café de qualidade; terminais de acompanhamento on-line das bolsas das mercadorias; a especialização de seus técnicos quanto às regras dos mercados de alta qualidade, participação na Specialty 
Coffee Association e de outros eventos anuais; bem como a organização de seminário anual para os cafeicultores e a formação de dirigentes e cafeicultores.

Muito importante para a comercialização da produção foi a compra, em 1993, de um armazém em Patrocínio, com capacidade inicial para 180.000 sacos de café beneficiado, maquinário de benefício e padronização eletrônica para 1.200 sacas/dia. Hoje, essa capacidade supera os 500.000 sacos ano e 3.000 sacas/dia. A compra foi feita em sistema de condomínio, em que os agricultores adquiriram quotas-partes, garantidas aos pequenos e médios por meio de um limite máximo de dez a cada um deles. Atualmente, existem outras cinco cooperativas nos municípios de Araxá, Araguari, Carmo do Paranaíba, Monte Carmelo e Unaí — também ajustadas às normas do Caccer com vistas a padronizar Café do Cerrado como denominação de origem.

A constituição dessas cooperativas levou à necessidade da criação de uma Central de Cooperativas dos Cafeicultores do Cerrado (Expocaccer), para operacionalizar a comercialização de todas as cooperativas filiadas. A seguir, foi criado um consórcio de exportação para adiantar o processo de intercâmbio de informação sobre preços com clientes internacionais por intermédio de um grupo de agricultores; a troca resultaria em um maior giro dos estoques.

Isso posto, concluímos: o surgimento de formas associativas entre os agricultores de café do Cerrado Mineiro confirma teses defendidas por Moyano (1988), e utilizadas por nós (ORTEGA, 1995), de que o desenvolvimento do capitalismo na agricultura levou a um processo de especialização e, assim, contribuiu para a criação de entidades representativas especializadas - as chamadas organizações por produto - a fim de canalizar reivindicações de grupos específicos de agricultores, no caso dos cafeicultores. Nesse processo, as antigas entidades de caráter unitário perderam a hegemonia para as entidades de caráter específico; por outro lado, diante da insuficiente representatividade política dessas entidades para encaminhar toda a demanda de grupos específicos, 
Território, certificação de procedência e a busca da singularidade:

ganham força, incentivadas pelas próprias organizações reivindicativas, formas associativas de caráter econômico, a exemplo da cooperativa e do consórcio. A isso, acrescentamos a mudança de perspectiva na representação - vale dizer, a especialização - e a intensificação dos vínculos com setores industriais específicos, que favorecem o surgimento de espaços de concertação entre agricultura e indústria; numa fase de desregulamentação como a atual, esses espaços facilitam a elaboração, a gestão e a fiscalização de toda a cadeia produtiva. Numa palavra, surgem organizações interprofissionais.

\subsection{A singularidade do produto}

Ao conquistar a Indicação Geográfica, o CACCER busca incorporar singularidade ao seu produto. Ele passa a incorporar particularidades em sua qualidade não associadas, necessariamente, a características inerentes ao produto, mas, sim, aos atributos de valores reconhecidos pelos consumidores e garantidos pelo selo de qualidade que a instituição atesta (KARPIK, 2007). De posse dessa conquista, o passo seguinte é busca pela denominação de origem, uma certificação que reforça ainda mais singularidade.

Karpik (2007:40-46) identifica os produtos singulares das seguintes maneiras: a) em função de sua multidimensionalidade e incerteza, pois nem sempre a definição dada ao produto pelos produtores coincide com a dos consumidores; b) definição individual do consumidor quanto à qualidade do produto, que orienta seu consumo, ao contrário do preço, como define a economia neoclássica; c) temos, na opacidade e no oportunismo, características de sua decisão de consumo; d) os mercados dos produtos singulares requerem, para reduzir essa opacidade, mecanismos de coordenação, que auxiliem os consumidores no julgamento e na redução da subjetividade; e) a concorrência pela qualidade é preponderante, mesmo que essa qualidade seja simbólica; e, como a qualidade é predominante, os preços não são explicados pela relação entre demanda e oferta.

Essa perspectiva de Karpik (2007) pode ser inscrita na abordagem da Nova Sociologia Econômica (NSE) contemporânea, que 
toma como referência fundamental as contribuições de Karl Polanyi (2000), particularmente, seu conceito de embeddedness (enraizamento, incrustação), em que defende que os mercados são construções sociais. Foram White (1981) e, posteriormente, Granovetter (1985) os pioneiros em centrar a discussão das origens sociais dos mercados e dirigir suas críticas aos pressupostos teóricos neoclássicos estabelecidos na Nova Economia Institucional. Buscando, portanto, uma terceira via, entre as concepções sub e hiper-socializadas da natureza humana, a NSE assinala "o primado da relação social, da confiança e das redes como tópicos dominantes num projeto de investigação profícuo", como destaca Marques (2003:4).

Não realiza a NSE, entretanto, uma rejeição liminar dos paradigmas da racionalidade e do normativismo, mas, sim, por meio da tese da incrustação, ressalta a origem social dos mercados e uma "outra" racionalidade. Nesse sentido, a NSE não se apega à estrita racionalidade dos atores sociais, pois relações continuadas entre os agentes econômicos determinam a não deserção e fidelidade no consumo de determinada marca, reforçam a confiança e viabilizam a cooperação.

Nesse sentido, a NSE procura estabelecer uma teoria complexa da ação e, como consequência, recusa: a) total racionalidade dos atores sociais, pois existem motivações multicritérios nas decisões; b) rejeita o imperialismo culturalista, que faz dos atores sociais "marionetes culturais"; e c) rejeita, ainda, o primado absoluto das posições estruturais, que explicam os quadros de reprodução social, mas não as mudanças (MARQUES, 2003:13).

A NSE ocupa-se, portanto, do estudo das chamadas formas impuras entre a solução mercantil e a solução de autoridade, buscando a "paixão" no interior da razão estritamente econômica. Ou seja, reconhece a NSE que as decisões dos atores econômicos são motivadas pela repetição das relações, o que implica levar em consideração a História, e por tentativas de antever o futuro. Nessa perspectiva, as influências exteriores não são nem anônimas e nem livres. Possuem mãos visíveis, que, no nosso caso, são estabelecidas pela confiança na certificação conferida ao café por meio da Certificação de Procedência. 
Território, certificação de procedência e a busca da singularidade:

o caso do Café do Cerrado

Para a NSE, portanto, as redes de relações sociais continuadas é que estão na base de contratos entre as organizações, grupos empresas e instituições. Assim, para a manutenção dessas relações, a confiança é um dos atributos mais importantes a ser destacado, mesmo porque ela possibilita que se alcance a cooperação ${ }^{9}$.

Em Karpik (2007), a confiança permite que se estabeleça relação com uma realidade simbólica e social e, nesse sentido, constitui-se uma relação institucionalizada composta não somente de conhecimento de informações (que pode ser dado pela certificação), mas também por crenças. Essas crenças, no caso de mercados de produtos certificados por sua origem, podem ser ainda mais consolidadas, uma vez que é grande a confiança na instituição, que reduz a incomensurabilidade dos produtos.

Nesse sentido, o consumidor de bens singulares, em vez de julgar por meio do conhecimento empírico, toma decisões em função das informações (no caso do café, por meio da classificação conferida pelo selo de qualidade). Por confiança delega às instituições que certificam o café o poder de julgamento sobre o produto a ser consumido, de acordo com a característica que o consumidor espera encontrar. Encontramos, nesse caso, o Homo singularis, que, assim como o Homo economicus, também toma decisões seguindo seus interesses, mas de acordo com uma racionalidade que se guia por uma pluralidade de valores, inclusive, simbólicas (BOURDIEU, 2007), e não por uma racionalidade maximizadora da utilidade.

\section{Transformações produtivas e diferenciação social}

O processo de intensificação da cafeicultura do Cerrado Mineiro, dentre outras transformações, provocou profundas modificações nas relações sociais de produção, com fortes impactos

9 A confiança é um dos temas mais importantes nas Ciências Sociais. Ela é vista como cimento da sociedade (ESLTER, 1991), variável fundamental nos dilemas da ação coletiva, tanto dos problemas da ação coletiva de Olson (1999), como da teoria da eleição racional (ESLTER, 1984). Porém, há que se observar que confiança não é bondade, não é altruísmo, mas uma relação que estabelece em função da repetição das ações dos atores sociais. Ou seja, da história. 
sobre o emprego rural. No primeiro momento, em que se introduziu essa cultura altamente demandante de força de trabalho, observou-se, por exemplo, uma elevação do emprego assalariado em detrimento de outras formas de ocupação (GARLIPP,1999). Entretanto, mais recentemente, intensifica-se a mecanização do processo produtivo, com destaque para a colheita, bastante ampliada em virtude da disseminação da prática de terceirização dessas atividades no meio rural do Cerrado Mineiro.

De outro lado, todo esse processo vem ampliando as exigências sobre os produtores, o que tem levado a uma grande diferenciação entre eles. Aspectos que têm levado à melhoria da qualidade dos frutos são a irrigação e a mecanização da colheita. Porém, tanto em um caso como no outro, exige-se reorganização produtiva para sua adoção.

Os métodos tradicionais de mecanização da colheita do café só são possíveis de ser aplicados em terrenos com declividade de até $20 \%$. Portanto, limitações, operacionais e econômicas mostram que a mecanização depende sempre da complementação do serviço braçal. Além disso, as máquinas necessitam de operadores, pessoal de manutenção, comercialização e assistência técnica, ou seja, mão-de-obra especializada, o que denota que, de um lado, se reduz o número de trabalhadores pouco qualificados, de outro, introduzem-se novos trabalhadores, mais qualificados.

A colheita do café é mais difícil de ser executada do que a de outros produtos, em razão da estrutura da planta, sua não uniformidade de maturação e do teor de umidade. Nessa etapa, as colheitadeiras, em determinadas condições de trabalho, chegam a fazer, em um dia de serviço, o equivalente a 250 homens, de acordo com dados da UFV (http://www.ufv..br/poscolheita/cafe/ indice.htm), acesso em 15/5/2006), embora alguns engenheiros agrônomos entrevistados digam que elas substituem de 180 a 200 trabalhadores em boas condições.

Na região do Cerrado Mineiro, a colheita inicia-se em maio e termina em setembro. Apesar da redução no número de traba- 


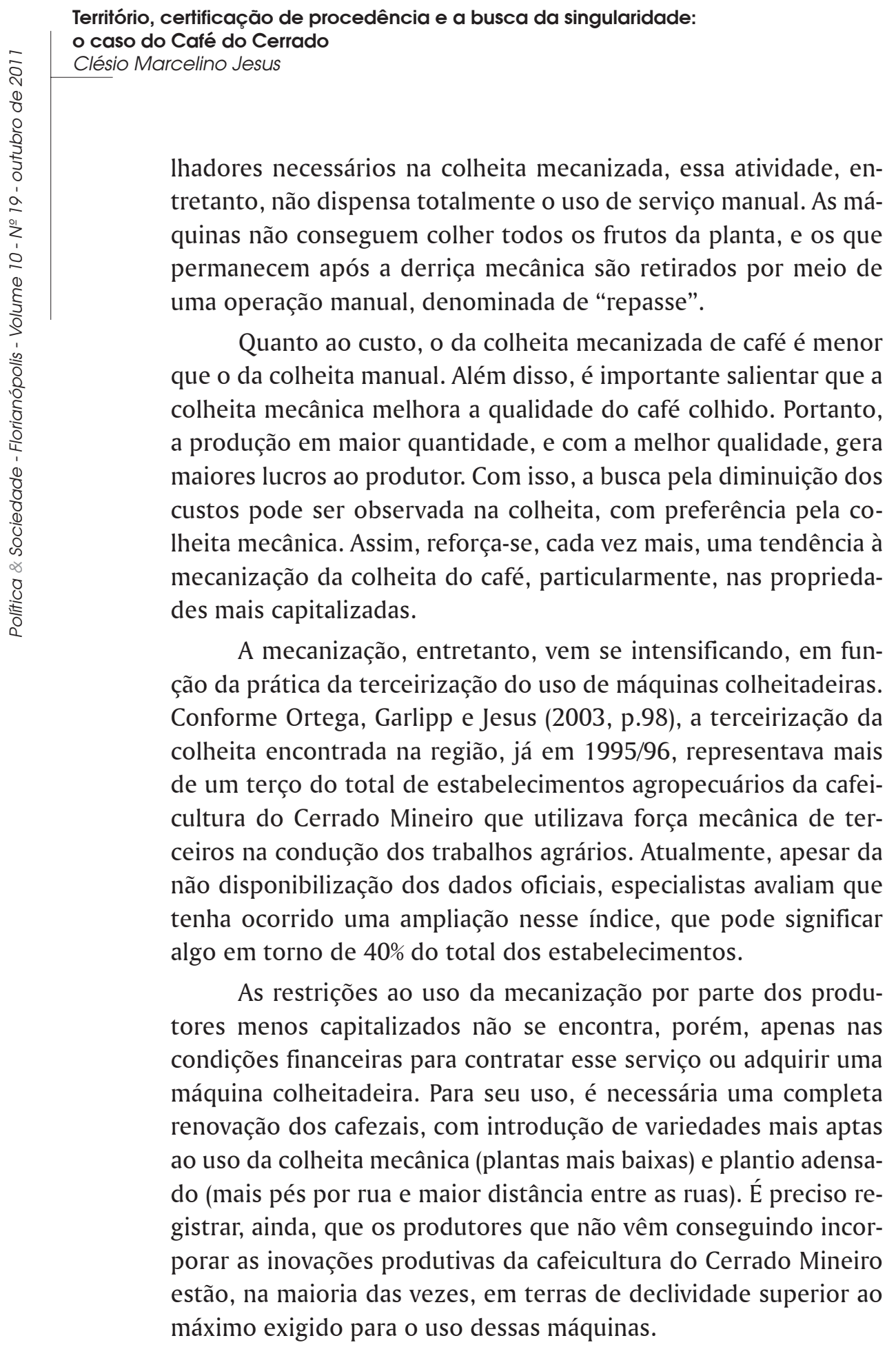




\section{Indicação geográfica e certificação: competividade e exclusão}

Para garantir a origem, a qualidade e idoneidade do modelo de produção e de rastreabilidade, o Caccer possui um sistema de georreferenciamento, com banco de dados das propriedades certificadas, que permite a localização da propriedade e a precisão de seus limites, a demarcação da área, bem como de reservas legais, altitude, declividade e cursos d'água, além do mapeamento completo das áreas de café.

O Cerrado Mineiro é a única região do mundo que certifica o café desde o local onde é plantado até o consumo. Inspirados nas experiências francesa e italiana, seus associados recebem um selo de denominação de origem controlada. Os cafeicultores certificados têm de seguir rígidas regras de produção, que proíbem o uso de mão-de-obra infantil, exige o registro em carteira de funcionários, o respeito às normas ambientais rígidas, a manutenção de reservas e matas ciliares, além de cuidados especiais no manuseio de produtos tóxicos, com o uso de equipamentos de proteção pelos trabalhadores durante as pulverizações. Com isso, as fazendas

certificadas recebem a chancela de uma até quatro estrelas, dependendo do número de itens que cumprem.

De acordo com a Portaria 38.559, de 17 de dezembro de 1996, da IMA (Instituto Mineiro de Agropecuária da Secretaria de Agricultura do Estado de Minas Gerais), o Cerrado Mineiro caminhava para obter a primeira indicação de procedência reconhecida pelo INPI. Em 1998, de acordo com o Registro N. 481.05.478, o Caccer foi credenciado pelo governo de Minas Gerais, por intermédio da IMA, como certificador de origem e qualidade de café, tornando-se a primeira entidade certificadora oficial de café do país.

O Caccer constitui-se, dessa maneira, no Certificador da Origem reconhecido pela OIC (Organização Internacional do Café), para a região demarcada do Cerrado Mineiro, devidamente credenciado segundo convênio com o Centro de Comércio de Café de 


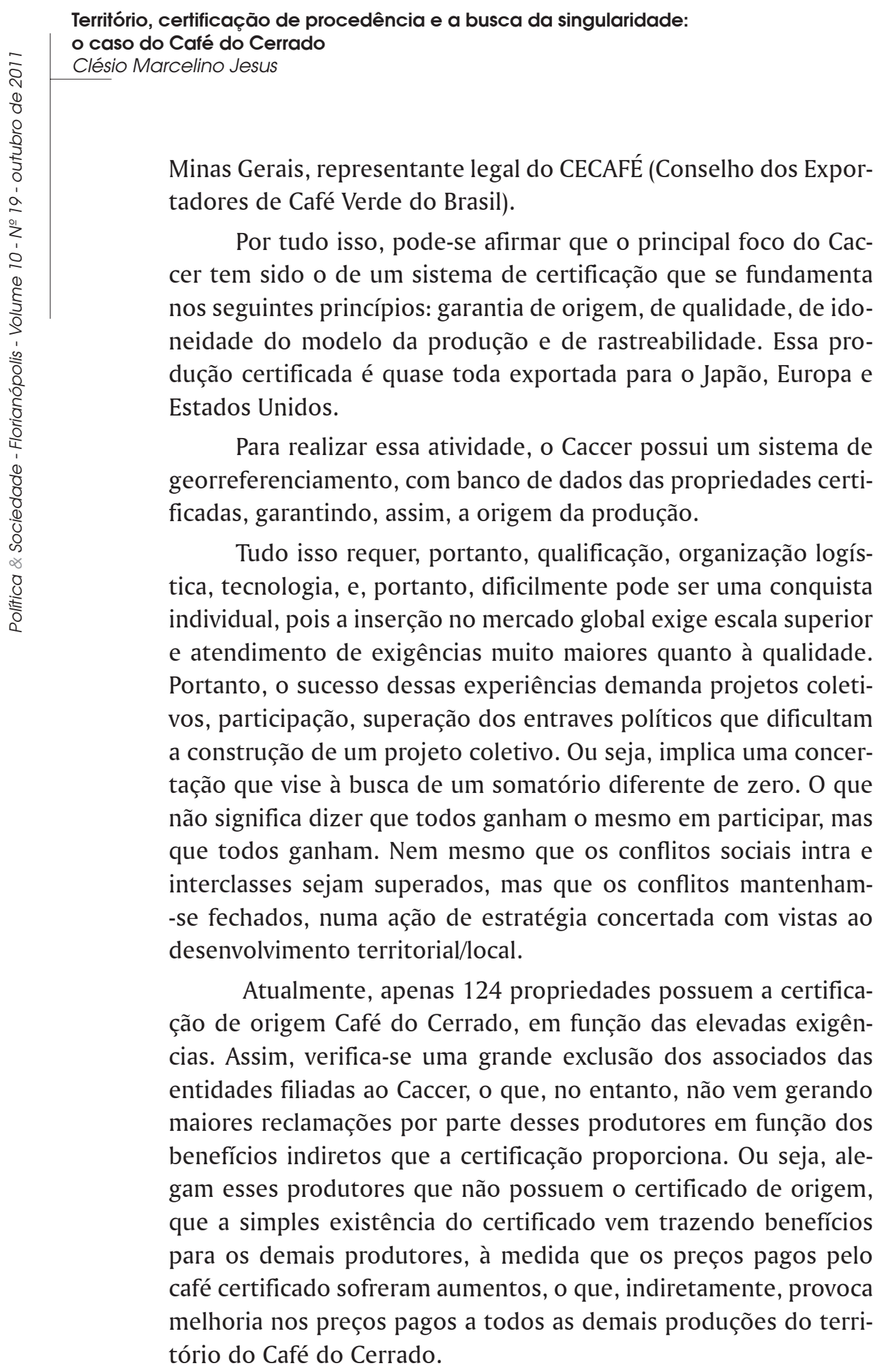


Assim, mais do que a certificação, a não inclusão de toda a base associativa da cafeicultura do Cerrado Mineiro ocorre em função da elevada exigência quanto à do produto, obtido em grande medida em função da introdução de inovações produtivas de alto custo, como é os casos da irrigação e da colheita mecânica, que exige completa renovação dos cafezais e boa localização, o que é dificultado para os produtores menos capitalizados, quase sempre, localizados nas piores terras, em função da inclinação do solo. Assim, possuem produtividade menor, custos de mão de obra maiores e preços menores por não possuírem a certificação de origem.

Uma última observação é que a busca pela certificação/diferenciação do produto vem ocasionando várias externalidades positivas nas propriedades e na região. Pois, no processo de certificação, as exigências a serem cumpridas: leis trabalhistas, ambientais e organização do processo produtivo, requerem mudanças em ações que antes eram degradantes. Como exemplo, temos a construção de um local para o recolhimento das embalagens de agrotóxico para a devida reciclagem das embalagens, que eram abandonadas no campo.

\section{Conclusão}

Ao analisar o caso do Café do Cerrado em Minas Gerais, reconhecemos que o sucesso daquela atividade está ligado à constituição de um arranjo produtivo territorial rural bastante institucionalizado, cuja inserção nos mercados nacional e global é cada vez mais expressiva. O êxito dessa experiência pode ser atribuído, em grande medida, a uma maior competitividade conferida pela certificação de origem do café. Entretanto, há que se reconhecer que esse processo tem causado profunda diferenciação entre os produtores e desemprego rural, em decorrência da intensificação da disseminação da colheita mecanizada.

Por outro lado, identificamos que a constituição de uma estrutura de governança bastante institucionalizada contribuiu com o sucesso da cafeicultura regional, consolidando um verdadeiro 
Território, certificação de procedência e a busca da singularidade:

o caso do Café do Cerrado

Clésio Marcelino Jesus

território do café. A capacidade organizativa dos cafeicultores em torno de suas associações de produtores e pelo Caccer, não se pode deixar de reconhecer, vem construindo as condições para o coroamento dessa participação e cooperação por meio da obtenção da Denominação de Origem, passo seguinte a atual Indicação de Procedência conquistada. Com isso, se explora a singularidade do produto obtido no Cerrado Mineiro para a conquista de mercados cada vez mais exigentes. Não obstante, não se pode deixar de reconhecer, também, que esse processo estabeleceu enormes exigências sobre os cafeicultores, que nem sempre conseguem acompanhar as inovações necessárias para se alcançar os níveis de produtividade e qualidade requeridas e acabam excluídos.

Recebido em: 06.02.2010

Aprovado em: 6.05.2011

\section{Referências}

BOURDIEU, P. O poder simbólico. Rio de Janeiro: Bertrand-Brasil, 2007.

FLIGSTEIN, N. O mercado enquanto política. Uma abordagem político-cultural às instituições de mercado. In: PEIXOTO, J. \& MARQUES, R. A nova sociologia económica. Oeiras-Portugal: Celta Editora, 2003.

BRASIL, Instituto Nacional da Propriedade Industrial - INPI. Apresenta informações sobre Indicação de Procedência. Acesso em 2009.

GARLIPP, Ana A. B. P. Mecanização e emprego rural: os casos do café e da cana-de-açúcar no Triângulo Mineiro e Alto Paranaíba (MG). Dissertação de mestrado. Instituto de Economia, Universidade Federal de Uberlândia, agosto de 1999.

GRANOVETTER, M. Ação econômica e estrutura social: o problema da incrustação. In: MARQUES, R. \& PEIXOTO, J. (org.). A Nova 
Sociologia Econômica: Uma antologia. Oeiras-Portugal: Celta Editora, 2003.

HAESBAERT, R. O Mito da Desterritorialização. Do "Fim dos Territórios" à Multiterritorialidade. Rio de Janeiro: Editora Bertrand, 2006. (2a Edição Revisada).

KARPIC, L. Léconomie des singularités. Paris: Editions Gallimard, 2007.

MARQUES, R. Os trilhos da Nova Sociologia Econômica. In: MARQUES, R. \& PEIXOTO, J. (org.) A Nova Sociologia Econômica: uma antologia. Oeiras-Portugal: Celta Editora, 2003.

MOHAR, A. Políticas de desarrollo y ordenamiento territorial. Bogotá, Seminário de Expertos sobre Biocombustibles: oportunidades, desafios y políticas, 5 a 7 de marzo de 2008.

MOYANO ESTRADA, E. El concepto de capital social e su utilidad para el análisis de las dinámicas del desarrollo. In: Revista Economia Ensaios. Vol. 13, n.2 e vol. 14, n. 1, jul-dez, 1999.

ORTEGA, A. C.; GARLIPP, A. A. D. ; JESUS, C. M. Terceirização e emprego rural na agricultura do cerrado mineiro: os casos da mecanização no café e na cana-de-açúcar. In: XLI Congresso da Sober, Juiz de Fora, Julho de 2003. Anais... Juiz de Fora, Julho de 2003.

ORTEGA, A. C.; MOURO, M. C. Mecanização e emprego na cafeicultura do cerrado mineiro. In: XLV Congresso da Sociedade Brasileira de Economia, Administração e Sociologia Rural. Conhecimento para a Agricultura do Futuro, 2007, BrasíliaLondrina. Anais... Brasília-Londrina: Sober, 2007. V. 1. P. 1-20.

ORTEGA, A. C. Agronegócios e representação de interesses no Brasil. Uberlândia: EDUFU, 2005.

PESSOA, V.L.S. Ação do Estado e as transformações agrárias no cerrado das zonas de Paracatu e Alto Paranaíba. Rio Claro: UNESP, 1989. (tese de doutorado).

POLANYI, K. A grande transformação. As origens de nossa época. Rio de Janeiro: Elsevier, 2000 (12 $2^{\mathrm{a}}$ reimpressão).

REIS, J. A globalização como metáfora da perplexidade? Os processos geoeconômicos e o 'simples' funcionamento dos 
Território, certificação de procedência e a busca da singularidade:

o caso do Café do Cerrado

Clésio Marcelino Jesus

sistemas complexos. In: SANTOS, B.S. A globalização e as Ciências Sociais. São Paulo: Editora Cortez, 2002.

RIBEIRO, A.E. A modernização dos cerrados. Belo Horizonte: CPTMG, 1985. (mimeo)

SALIM, C.A. As políticas econômicas e tecnológicas para o desenvolvimento agrário das áreas de cerrado no Brasil: avaliação e perspectivas. In: Cadernos de Difusão de Tecnologia. Brasília, 3(2), mai-ago, 1986.

SEPÚLVEDA, S.; RODRIGUEZ; A.; ECHEVERRI, R.; Y PORTILLA, M. El Enfoque Territorial Del Desarrollo Rural. San José, IICA, 2003.

WHITE, H.C. Where do markets come from? American Journal of Sociology, 87, 1981. p. 517-547.

\begin{abstract}
Territory, certification of precedence and the search of the singularity: the case of the 'Coffee of Cerrado'

This article analyzes the experience of the territorial productive arrangement organized by coffee growers in the west of Minas Gerais (Brazil), who, by means of their municipal producers associations, have constituted the Coffee Growers Association Council of Cerrado that obtained, in 2005, the recognition of their coffee Geographical Indication, and started to emit the Certification of Precedence 'Coffee of Cerrado'. The role of the Council is to accredit the quality of the production of its affiliated that meet the specifications demanded by that certification. Coffee of Cerrado was, then, the first demarcated area of the country to produce coffee. The success of that coffee growing is linked to the constitution of a territorial productive rural arrangement, quite institutionalized, whose insertion in the national and global markets has been increasingly more expressive. However, it is necessary to recognize that this process has provoked differentiation among producers, mainly between those that have and those other that have not been able to meet the established demands by the origin certification.
\end{abstract}

Keywords: coffee growing, Coffee of Cerrado, origin certification, new economic sociology, territorial development. 